\begin{tabular}{|c|c|c|c|c|}
\hline Share: Social Work Jurnal & VOLUME: 10 & NOMOR: 1 & HALAMAN: $91-95$ & $\begin{array}{c}\text { ISSN: 2339-0042 (p) } \\
\text { ISSN: 2528-1577 (e) } \\
\text { DOI: 10.24198/share.v10i1.26896 }\end{array}$ \\
\hline
\end{tabular}

\title{
PROSES REKRUITMENT PEKERJA SOSIAL DI INSTITUSI PENERIMA WAJIB LAPOR INABAH XV PONDOK PESANTREN SURYALAYA
}

\author{
Oleh : \\ Ahmad Saalik Hudan Alfariz ${ }^{1}$, Soni A. Nulhaqim² ${ }^{2}$ Santoso T. Raharjo 3 \\ ${ }^{1}$ Mahasiswa Pascasarjana Kesejahteraan Sosial, FISIP - Universitas Padjadjaran \\ (saalikhudan@gmail.com) \\ 2, 3 Pusat Stusi CSR, Kewirausahaan Sosial \& Pemberdayaan Masyarakat, FISIP - Universitas Padjadjaran \\ (soni.nulhaqim@unpad.ac.id)
}

\begin{abstract}
ABSTRAK (bold, 10 Point).
Tujuan dari penelitian ini adalah untuk menggambarkan proses rekruitmen pekerja sosial adiksi di Inabah XV Pondok Pesantren Suryalaya sebagai institusi penerima wajib lapor kementerian sosial, mengingat pentingnya proses rekruitmen untuk menemukan individu yang kompeten untuk mencapai tujuan organisasi. Penelitian ini dilakukan di Inabah XV Pondok Pesantren Suryalaya. Metode yang digunakan dalam penelitian ini adalah deskriptif kualitatif. Deskriptif kualitatif adalah metode yang menginterpretasikan data yang telah dikumpulkan untuk mendapatkan deskripsi yang komprehensif tentang situasi aktual. Data dikumpulkan melalui wawancara dengan pimpinan Inabah XV Pondok Pesantren Suryalaya dan studi literatur. Analisis data dengan mengurangi dan menampilkan sampai dapat disimpulkan. Hasilnya menunjukkan bahwa proses rekruitmen sudah dilaksanakan dengan tahapan mengumumkan lowongan kerja, mengidentifikasi pelamar yang potensial, menyebarkan pengumumam rekrutmen, memproses aplikasi para pelamar, dan menentukan deadline proses lamaran hingga seleksi.

Kata kunci: proses rekruitmen, pekerja sosial adiksi
\end{abstract}

\section{ABSTRACT (bold, 10 Points).}

The purpose of this study is to describe the recruitment process of addiction social workers at Inabah XV Pondok Pesantren Suryalaya as an institution that receives mandatory reports from the Ministry of Social Affairs, given the importance of the recruitment process to find competent individuals to achieve organizational goals. This research was conducted at Inabah XV Pondok Pesantren Suryalaya. The method used in this research is descriptive qualitative. Qualitative descriptive is a method that interprets the collected data to get a comprehensive description of the actual situation. Data were collected through interviews with the leaders of Inabah XV Pondok Pesantren Suryalaya and literature studies. Data analysis by reducing and displaying until it can be concluded. The results show that the recruitment process has been carried out with the stages of announcing job vacancies, identifying potential applicants, spreading recruitment announcements, processing applicants' applications, and setting deadlines for the application process to selection.

Keywords: recruitment process, addiction social worker 


\begin{tabular}{|c|c|c|c|c|}
\hline Share: Social Work Jurnal & VOLUME: 10 & NOMOR: 1 & HALAMAN: $91-95$ & $\begin{array}{c}\text { ISSN: 2339-0042 (p) } \\
\text { ISSN: 2528-1577 }(e) \\
\text { DOI: 10.24198/share.v10i1.26896 }\end{array}$ \\
\hline
\end{tabular}




\section{Pendahuluan}

Pola dasar pembangunan nasional meletakkan dasar-dasar bagi pembangunan bangsa dan mewujudkan pembangunan nasional. Dalam pola dasar juga dilandaskan bahwa pembangunan nasional pada hakekatnya adalah pembangunan manusia seutuhnya yang meliputi berbagai bidang kehidupan diantaranya ideologi, politik, ekonomi, sosial, budaya, dan pertahanan keamanan. Dalam era global ini, bidang ekonomi telah menetapkan diri dalam perkembangan yang sangat pesat, seiring dengan perkembangan ilmu pengetahuan dan teknologi yang ditunjukkan untuk meningkatkan kesejahteraan masyarakat. Oleh sebab itu perkembangan tersebut memaksa manusia baik secara individu maupun kelompok untuk senantiasa berkompetisi, dalam kaitannya dengan hidup dan kehidupan khususnya pada kegiatan perekonomian yang semakin ketat dan berkompetisi ini. Institusi Penerima Wajib Lapor atau selanjutnya dapat juga di sebut dengan IPWL. IPWL merupakan Program wajib lapor bagi Pengguna, Korban Penyalahguna, Dan Pecandu Narkotika merupakan Program yang diatur dalam Peraturan Pemerintah No. 25 tahun 2011 tentang wajib lapor Institusi Penerima Wajib Lapor, Ditunjuk oleh 2 Kementrian Kesehatan Dan Kementrian Sosial. Kementrian Kesehatan khusus menunjuk Lembaga/ Institusi kesehatan di bawahnya yakni RS. Ketergantungan Obat, Puskesmas, RSJ, dll.

Kementrian Sosial menunjuk Lembaga/Institusi Sosial masyarakat yakni Lembaga Swadaya Masyarakat Dan Panti Rehabilitasi sosial di bawah binaan Kementrian Sosial. Kedudukan Institusi Penerima Wajib Lapor (IPWL) terhadap undang-undang no. 35 tahun 2009 tentang narkotika dapat kita lihat di dalam undangundang tersebut pada bab IX bagian kedua tentang Rehabilitasi pada pasal 55 yang berbunyi (1) Orang tua atau wali dari pecandu Narkotika yang belum cukup umur wajib melaporkan pada pusat kesehatan masyarakat, rumah sakit, dan/atau lembaga rehabilitasi medis dan sosial yang ditunjuk oleh pemerintah untuk mendapatkan pengobatan dan/atau perawatan melalui rehabilitasi medis dan rehabilitasi sosial. (2) Pecandu Narkotika yang sudah cukup umur wajib melaporkan diri atau dilaporkan oleh keluarganya kepada pusat kesehatan masyarakat, rumah sakit, dan/atau lembaga rehabilitasi medis dan rehabilitasi sosial yang ditunjuk oleh Pemerintah untuk mendapatkan pengobatan dan/atau perawatan melalui rehabilitasi medis dan rehabilitasi sosial

Keberadaan Lembaga Kesejahteraan Sosial yang bergerak di bidang penanggulangan penyalahgunaan NAPZA khususnya dalam bidang rehabilitasi sosial korban penyalahgunaan NAPZA yang semakin meningkat jumlah dan cakupannya memperlihatkan adanya partisipasi dan kepedulian masyarakat dalam penanggulangan penyalahgunaan NAPZA. Sebagai implementasi dari Peraturan Pemerintah Nomor 25 tahun 2011 tentang Pelaksanaan Wajib Lapor Pecandu Narkotika. Salah satu tujuan IPWL adalah untuk memenuhi hak pecandu narkotika dalam mendapatkan pengobatan dan/atau perawatan melalui rehabilitasi medis dan rehabilitasi sosial.

Oleh karena itu, IPWL dituntut untuk terus menerus meningkatkan kualitas kemanfaatan pelayanannya agar ke depan dapat menjadi bagian dari solusi strategis pemecahan masalah yang dialami para korban penyalahgunaan NAPZA. Pada posisi peran seperti itu IPWL mampu menyediakan banyak sumber, baik sumber 
pengetahuan, keterampilan, maupun sumber lain yang relevan dengan kebutuhan masyarakat, baik kebutuhan sosial maupun ekonomi, khususnya kebutuhan kelompok warga negara miskin, rentan dan marjinal. Salah satu upaya Kementerian Sosial untuk mewujudkan harapan IPWL sebagai resources-based adalah melalui penyelenggaraan kegiatan Usaha Ekonomi Produktif bagi korban penyalahgunaan NAPZA.

Salah satu lembaga swasta yang menjadi IPWL ditujukan untuk membantu pemerintah memberikan pelayanan rehabilitasi untuk korban penyalahguna NAPZA ini adalah Pondok Pesantren Suryalaya, Kabupaten Tasikmalaya, Provinsi Jawa Barat. Pondok Pesantren Suryalaya ini sudah berdiri sejak tanggal 5 september tahun 1905, yang didirikan oleh almarhum Syekh H Abdullah Mubarok Bin Nur Muhammad yang terkenal dengan julukan abah sepuh. Pengurus pesantren bersedia membantunya dengan membina anak tersebut untuk kembali pada kesucian dan tidak ketergantungan NAPZA lagi melalu metode Inabah $\mathrm{XV}$, dari metoed tersebut kegiatan yang dilaksanakannya adalah mandi, dzikir dan solat serta kegiatan ibadah lainnya seperti puasa dan mengikuti makabina yaitu pengajian yang diadakan oleh pihak pesantren, agar korban ketergantungan NAPZA tidak kembali lagi pada jalan yang salah, atau kembali menyalahgunakan NAPZA. Kementerian sosial mewajibkan setiap IPWL harus memiliki pekerja sosial untuk memberikan dan mengontrol pelayanan rehabilitasi yang akan diberikan oleh setiap lembaga yang terdaftar menjadi IPWL. Untuk memperoleh atau mendapatkan peluang jabatan tersebut perlu dilakukan rekrutmen yang dilakukan oleh Kementerian Sosial sehingga dapat diperoleh pegawai yang berkualitas sesuai dengan kebutuhan.

Peniliti memfokuskan penelitian ini pada proses rekruitmen pekerja sosial di IPWL, suatu organisasi atau organisasi terlebih dahulu melakukan proses rekrutmen, yang meliputi: pengumuman lowongan kerja, mengidentifikasi pelamar yang potensial, menyebarkan pengumumam rekrutmen, memproses aplikasi para pelamar, dan menentukan deadline proses lamaran hingga seleksi (Kettner, 2002). Berdasarkan uraian di atas, maka penulis tertarik untuk meneliti dan mengkaji lebih dalam dan menuangkan dalam sebuah tulisan yang berjudul "ANALISIS PROSES REKRUITMENT PEKERJA SOSIAL DI INSTITUSI PENERIMA WAJIB LAPOR INABAH $\quad X V$ PONDOK PESANTREN SURYALAYA".

\section{Metode}

Metode yang digunakan dalam penelitian ini adalah deskriptif kualitatif. Penelitian kualitatif adalah penelitian yang menggunakan kata-kata untuk menceritakan suatu fenomena atau gejala (Creswell, 2009). Metode penelitian kualitatif deskriptif adalah metode yang menginterpretasikan data yang telah dikumpulkan untuk mendapatkan deskripsi yang komprehensif tentang situasi aktual. Jenis data yang digunakan dalam penelitian ini adalah data primer dan sekunder. Data primer diperoleh dari informan, Pimpinan Inabah VX Pondok pesantren Suryalaya, sedangkan data sekunder diperoleh dari web dan dokumen lainnya. Teknik pengumpulan data dalam penelitian ini melalui wawancara dengan informan dan studi literatur. Penelitian ini dilakukan di Inabah VX Pondok Pesantren Suryalaya. Penilitan ini difokuskan untuk mendapatkan informasi mengenai bentuk pengumuman lowongan kerja, 
karakteristik pelamar potensial yang dibutuhkan IPWL, dan deadline lamaran hingga proses seleksi.

\section{Hasil dan Pembahasan}

Proses rekrutmen, yang meliputi: pengumuman lowongan kerja, mengidentifikasi pelamar yang potensial, menyebarkan pengumumam rekrutmen, memproses aplikasi para pelamar, dan menentukan deadline proses lamaran hingga seleksi (Skidmore, 1995). Di Inabah VX pondok pesantren surlaya, proses rekrutmen ini mengikuti kebijakan langsung yang diberikan oleh kementerian sosial, proses rekrutmen dan seleksi dilaksanakan oleh kementerian sosial dengan syarat IPWL yang bersangkutan mengajukan permohonan SDM pekerja sosial, kementerian sosial bertanggung jawab sepenuhnya dalam pelaksanaan rekrutmen dan seleksi pekerja sosial secara keseluruhan. Pihak Inabah hanya memberikan daftar calon pekerja sosial yang dibutuhkan oleh Lembaga, akan tetapi kualifikasi keahlian Pekerja Sosial semua diatur oleh Kementerian Sosial.

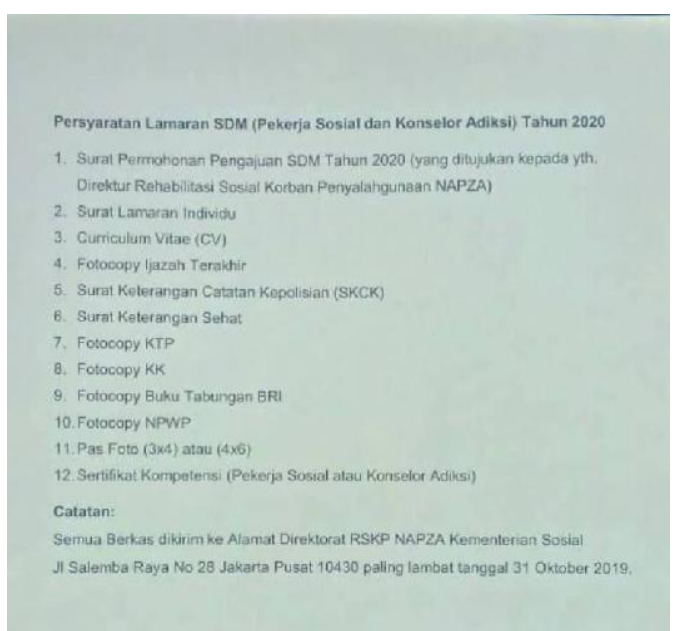

Gambar 1. 1 Pengumuman Lamaran SDM Pekerja Sosial Adiksi Tahun 2020

Pengumuman lowongan kerja yang disampaikan kepada IPWL, kementerian sosial menjelaskan secara spesifik posisi yang akan dilamar oleh para pelamar tersebut, sehingga para pelamar mendapatkan gambaran serta informasi mengenai deskripsi kerja yang akan mereka lakukan jika menempati posisi tersebut. Informasi seperti itu yang harus diperhatikan oleh Lembaga yang membuka lowongan pekerjaan sangat penting dalam proses rekrutmen, karena menjadi salah satu pencegah turnover pegawai di kemudian hari (Skidmore, 1995). Bentuk pengumuman ini kurang menarik dan lebih bersifat privat tidak bersifat publik, karena memang pengumuman ini dibuat oleh kementerian sosial hanya untuk IPWL. Dalam selembaran yang ditujukan untuk rekruitmennya pun tidak berisi pengumuman yang detail, hanya kualifikasi untuk pekerja sosial adiksi dan persyaratan melamar dan batas waktu mengumpulkan berkas. Penulis berasumsi bahwa pengumuman ini lebih seperti persyaratan melamar kerja bukan pengumuman rekruitmen.

Proses aplikasi para pelamar, dalam edaran rekruitmen pekerja sosial adiksi proses aplikasinya pelamar hanya diminta mengirim berkas yang dimohon ke alamat RSKP NAPZA Kementerian Sosial JI. Salemba Raya No. 28 Jakarta Pusat dengan cara laring. Proses ini dianggap sangat kuno karena proses aplikasi ini tidak melalui proses daring, padahal kementerian sosial mampu melakukan rekruitmen pekerja sosial ini dengan proses daring.

Deadline proses lamaran dicantumkan dalam edaran rekruitmen pekerjasosial adiksi, tertara pada edaran tersebut paling lambat tanggal 31 Oktober 2019. Akan tetapi proses pengumuman seleksi dan kelolosan administrasi ini menjadi hambatan karena diberlakukannya proses luring atau offline, para calon pelamar mengalami 
kebingungan saat menantikan hasil seleksi administrasi. Selain itu, terjadinya inkonsistensi dalam pelaksanaan seleksi pekerjasosial adiksi, tanpa memberitahu sebab terjadinya perubahan jadwal seleksi tersebut

\section{Kesimpulan dan Saran}

Kesimpulan dari hasil wawancara, observasi dan studi dokumentasi yang dilakukan peneliti, munculah kesimpulan tentang proses rekruitmen pekerja sosial adiksi yang dilakukan IPWL berupa pengumuman lowongan kerja yang tidak bersifat transparan atau tidak ditujukan untuk publik, proses identifikasi pelamar yang potensial cukup jelas dapat dilihat dari persyaratan yang ditujukan untuk pelamar, penyebaran pengumumam rekrutmen bersifat tertutup karena hanya ditujukan kepada pimpinan IPWL, proses aplikasi para pelamar besifat luring yang mengakibatkan calon pelamar sulit mendapatkan informasi, penentuan deadline proses lamaran hingga seleksi jelas tertara pada pengumuman.

Saran untuk proses rekruitmen IPWL sebaiknya dilakukan dengan proses during/online agar memudahkan para pelamar mendapatkan informasi, selain itu pengumuman lowongan ini harus bersifat publik.

\section{Daftar Pustaka}

Adi Fahrudin. 2012. Pengantar IImu Kesejahteraan Sosial. Bandung : PT. Refika Aditama

B. Harsono,"Analisisprosesrekrutmenkarya wanpadadirektoratsumber daya manusia (sdm) informasi dan umum di fungsi hr operations pt pertamina (persero)," Public Adm. J., vol. 2, no. 2, pp. 232-252, 2018

Departemen Sosial RI, Buku Saku Pekerja Sosial. Jakarta: Depsos, 2004.
Dwi Heru Sukoco. 1991. Profesi Pekerjaan Sosial dan Proses Pertolongannya, Bandung: Koperasi Mahasiswa Sekolah Tinggi Kesejahteraan Sosial.

Garvin. 2011. Group Work. Bandung: STKS Press.

Greesberg, J. S. 2002. Comprehensive Stress Management. (2nd.). Newyork: McGraw Hill.

Hardjana, A. M. 2002. Stress tanpa distress: Seni mengelola Stress. (7th ed.) Yogyakarta: Kanisius.

Hawari, Dadang. 2001. Manajemen Stress, Cemas dan Depresi. Jakarta : Balai Penerbit FKUI

J. W. Creswell, "Research Design: Qualitative, Quantitative, and Mixed Methods Approaches." SAGE Publication, United States of America, p. 296,2009

Juda Damanik. 2008. Pekerjaan Sosial Jilid I. Jakarta: Direktorat Pembinaan Sekolah Menengah Kejuruan, Drektorat Jendral Manajemen Pendidikan Dasar dan Menengah, Departemen Pendidikan Nasional.

Johnson, Jerry L. (2004). Fundamental of Subtance Abuce Practice. Australia, Canada, Mexico, Singapore, Spain, United Kingdom, United Stated: Thomson Brools/cole.

Kettner, P.M. (2002). Achieving Excellence in the Management of Human Service Organizations. Boston: Allyn and Bacon.

Marbun, Jumayar. (2017) Pekerja Sosial dengan NAPZA/Narkoba. Bandung: STKS PRESS

Moh. Nazir. 2014. Metode Penelitian. Bogor: Ghalia Indonesia.

Parasian Simanungkalit. 2011, Globalisasi Peredaran Narkoba dan Penanggulangannya di Indonesia. Jakarta Selatan: Yayasan Wajar Hidup 


\begin{tabular}{|c|c|c|c|c|}
\hline Share: Social Work Jurnal & VOLUME: 10 & NOMOR: 1 & HALAMAN: 91 - 95 & $\begin{array}{c}\text { ISSN: 2339-0042 (p) } \\
\text { ISSN: 2528-1577 }(e) \\
\text { DOI: 10.24198/share.v10i1.26896 }\end{array}$ \\
\hline
\end{tabular}

Potter \& Perry. 2005. Fundamental Of Nursing: Concept, Process \& practice. (Renata Komalasari. Et. All, Penerjemah) Jakarta: EGC 2005

Rasmun. 2004. Stress, koping dan Adaptasi Teori dan Pohon Masalah Keperawatan. Jakarta: CV Sagung Seto

Romas, j. A., \& Sharma, M. 2000. $A$ Comprenhennsive Workbook For Managing Change \& promoting Helt. (2 nd.). Massachusett: Allyn $\&$ bacon.

Sarafino, E. P. 2008. Helth psycology: Biopschosicial Interaction (6th ed.). New York: John Wiley \& Sons

Setiani, Baiq. 2013. Kajian Sumber Daya Manusia dalam Proses Rekrutmen Tenaga Kerja di Perusahaan. Jurnal Ilmiah WIDYA, Volume 1 Nomor 1 Mei-Juni 2013.

Skidmore, Rex A. 1991. Introduction to Social Work. Fifth Edition. Prentice-Hall International Inc..

Smeltzer. S. C \& Bare. B. G. 2008. Brunner \& Sudarth's textbook Of Medical Surgical Nursing. Volume 1.(11 $1^{\text {th }}$ ed). Philladelpia: Lippicont

Sugiyono. 2011. Metode penelitian kuatitatif, kualitatif dan R\&D. Bandung: Alfabeta

Sugiyono. 2015. Penelitian Pendidikan: Pendekatan Kuantitatif, Kualitatif dan R\&D. Bandung: Alfabeta.

Weiten, W. 2007. Psychology: themes \& variations. (7th ed). United states of America: Thomson Wadsworth

Yusuf, S. 2004. Mental Hydiene: Pengembangan kesehatan Mental dalam Kajian Psikologi dan agama. Bandung; Pustaka Bani Qurasy.

\section{Sumber Lain}

Buku pedoman pelaksanaan rehabilitasi di Inabah VX Inabah Pondok Pesantren Suryalaya

Undang-Undang Nomor 5 Tahun 1997 tentang Psikotropika.

Undang-Undang Nomor. 35 Tahun 2009 Mengenai Narkotka.

http://regional.kompas.com/read/2010/03 /05/20274591/Sudah.7.Santri.Ina bah.Ditemukan.Tewas (diakses pada pukul 09.00, Selasa, 08 Agustus 2010)

http://repository.usu.ac.id/bitstream/1234 56789/38090/4/Chapter\%20II.pd f (Diakses pada Rabu 09 Agustus 2017 pukul 16.00)

Start An Addiction Social Work Career. 2013.

http://careersinpsychology.or/psy chology-careers/. (diakses pukul 16:58, Rabu, 09 Agustus 2017).

Undang-Undang Nomor 5 Tahun 1997 tentang Psikotropika.UndangUndang Nomor. 35 Tahun 2009 Mengenai Narkotika 